\title{
COTAS DE RESERVA AMBIENTAL: \\ UMA INTERPRETAÇÃO DA ANÁLISE ECONÔMICA DO DIREITO
}

ANTÔNIO JOSÉ MARISTRELLO PORTO ${ }^{\dagger}$

LAURA MENEGHEL DOS SANTOS ${ }^{\dagger}$

\section{UM DOSSIÊ SOBRE ANÁlise ECONÔMICA DO DIREITO}

ReSUMO: No Novo Código Florestal (Lei no 12.651/2012), a obrigação dos proprietários rurais de manter uma área de vegetação nativa (ou Área de Reserva Legal - ARL) foi flexibilizada pela introdução das Cotas de Reserva Ambiental (CRA). Por meio da organização de um Mercado de compensação, as CRA permitem que proprietários rurais com déficit de ARL regularizem sua situação por meio da compra de CRA daqueles com superávit de ARL (limitado ao mesmo bioma). Através de revisão bibliográfica e pesquisa jurídica, analisamos as especificidades dos arranjos institucionais estabelecidos para funcionamento desse instrumento. Utilizando o referencial analítico da AED, foi possível notar que o referido instrumento econômico de gestão ambiental, ao tentar estabelecer um sistema econômico mais eficiente e sustentável via internalização de externalidade, engendra uma alocação especifica de direitos de propriedade tácitos relativos ao meio ambiente. Mas, para que tal instrumento seja exitoso na promoção de preservação florestal, é

\footnotetext{
${ }^{\dagger}$ Doutor em Direito pela University of Illinois, Professor Pesquisador da Fundação Getúlio Vargas Direito-Rio (FGV Direito Rio) e Coordenador do Centro de Pesquisa em Direito e Economia da FGV Direito Rio.

† Doutoranda e Mestra em Políticas Públicas, Estratégias e Desenvolvimento pelo Instituto de Economia da Universidade Federal do Rio de Janeiro (UFRJ) e Bacharel em Ciências Econômicas pela Universidade Estadual de Campinas (Unicamp).
} 
preciso garantir direitos de propriedade seguros e um monitoramento efetivo da norma.

Palavras-CHAVe: Código Florestal; Regulação Ambiental; Análise Econômica do direito.

ABSTRACT: In the New Forest Code (Law no. 12.651/2012), the rural landowners' obligation to maintain an area with native vegetation cover (or Legal Reserve Area - LRA) was made more flexible by the introduction of Environmental Reserve Quotas (ERQ). Through the organization of a compensation market, ERQs allow rural landowners with LRA deficits to regularize their situation by purchasing ERA from those with an LRA surplus (limited to the same biome). Through bibliographic review and legal research, we seek to analyze the specificities of the institutional arrangements established for this instrument's operation. Using the analytical framework of the AED, it was possible to note that this economic instrument of environmental management, in an attempt to establish a more efficient and sustainable economic system through the internalization of externality, generates a specific allocation of property rights related to the environment. But for such an instrument to be successful in promoting forest preservation, it is necessary to ensure secure property rights and effective monitoring of the norm.

KEYWORDS: Forest Code; Environmental Regulation; Economic Analysis of Law. 


\section{SUMÁRIO:}

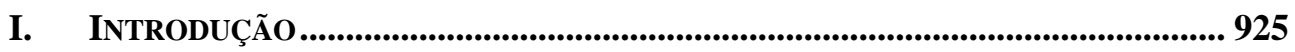

II. Políticas ambientais e Sistemas de Certificados Negociáveis......... 927

III. O Novo Código E AS Cotas de RESERVA AMBIENTAIS ..............................930

IV. DIREITOS DE PROPRIEDADE NO MERCADO DE CRA ...................................... 934

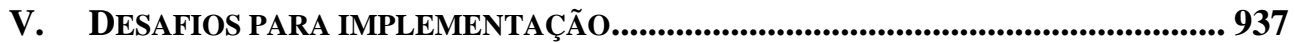

VI. CONSIDERAÇÕES FINAIS .................................................................................................. 944

VII. REFERÊNCIAS......................................................................................................... 945

\section{TABLE OF CONTENTS:}

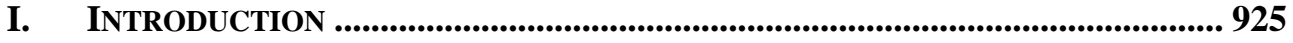

II. EnVironmental Policy AND Negociable Certificate Systems ......... 927

III. THE NEW STATUTE AND THE ENVIRONMENTAL RESERVE QUOTAS .............. 930

IV. PROPERTY RightS IN THE CRA MARKET ........................................................ 934

V. IMPLEMENTATION CHALLENGES.......................................................................... 937

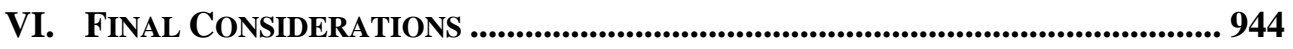

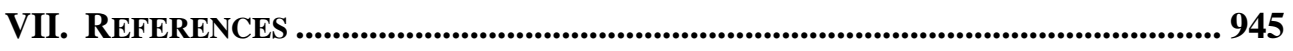




\section{INTRODUÇÃO}

O meio ambiente, por intermédio dos recursos naturais, fornece diversos benefícios à vida humana, desde alimentos e matérias-primas, até a estabilização do clima, a ciclagem de nutrientes e outros. No último século, os bens e serviços ambientais tornaram-se cada vez mais escassos pelo excesso de competição atribuível ao incremento demográfico e padrões de consumo.

Como consequência, a intensificação dos fenômenos associados às mudanças climáticas (como tempestades e secas) e a maior informação da população acerca dos prejuízos desse modelo de desenvolvimento - que desconsidera a importância e finitude dos recursos naturais - demandam uma maior atuação dos Estados como conciliador dos interesses da sociedade.

A legislação florestal brasileira opõe diversos interesses econômicos, sociais e ambientais. O regime anterior, do Código Florestal de 1965, não se mostrou efetivo em promover a proteção das coberturas florestais presentes em imóveis rurais. Diversas foram as razões, desde políticas públicas contraditórias de incentivo da ocupação do território, passando pela dificuldade de monitoramento e fiscalização dessas áreas em um país de dimensões continentais, até as inúmeras alterações na legislação florestal.

Anteriormente a promulgação do Código Florestal de 2012 (também chamado de Novo Código Florestal Brasileiro), alguns levantamentos apontaram que, dos 537 milhões de hectares (Mha) remanescentes de vegetação nativa no Brasil, somente 170 Mha correspondiam a áreas de conservação (federais e estaduais) e reservas indígenas. ${ }^{1}$ A maioria dos 367 Mha restantes está localizada em propriedades privadas de uso agrícola. Em relação a obrigatoriedade da manutenção, nas propriedades rurais, de uma área com vegetação nativa ou Área de Reserva Legal $(A R L)$ - cuja função é "assegurar o uso econômico de modo sustentável dos recursos naturais do imóvel rural, auxiliar a conservação e a reabilitação dos processos ecológicos e promover a conservação da biodiversidade, bem como o abrigo e a proteção de fauna silvestre e da flora nativa" ${ }^{2}$ - as

${ }^{1}$ SPAROVEK, Gerd, et. al.. Brazilian Agriculture and Environmental Legislation: Status and Future Challenges. Environmental Science and Technology, Vol. 44, 16, 2010. Disponível em: <http://pubs.acs.org/doi/abs/10.1021/es1007824>. Acesso em 19 de fevereiro de 2018.

${ }^{2}$ Lei $\mathrm{n}^{\mathrm{o}}$ 12.651/2012, art. $3^{\circ}$, inciso III. 
estimativas apontavam um déficit ${ }^{3}$ de 43 Mha em relação ao que seria necessário para o cumprimento da norma. ${ }^{4}$

O Novo Código Florestal, em seu artigo 44, instituiu a Cota de Reserva de Ambiental (CRA) como forma de fomentar um mercado de compensação de Áreas de Reserva Legal $(A R L)$. A ARL vem prevista pelo artigo 12 do Novo Código Florestal e constitui obrigação que recai sobre todo imóvel rural no Brasil consistente na manutenção de cobertura de vegetação nativa em percentuais que variam de $20 \%$ a $80 \%$ da área total do imóvel. ${ }^{5}$ A CRA permite que proprietários rurais com déficit de ARL regularizem sua situação por meio da compra de CRA daqueles com superávit de ARL (limitado ao mesmo bioma, conforme mapa do IBGE). Diferenças nos custos de oportunidade da terra fazem com que seja menos oneroso conservar ou restaurar florestas em áreas com rendimentos agrícolas mais baixos do que em áreas de valor agrícola mais alto. ${ }^{6}$ Assim sendo, por meio da CRA seria possível alcançar maior compatibilidade com a lei a um menor custo.

A CRA surge quase como uma atualização da Cota de Reserva Florestal (CRF), instituída pela Medida Provisória 2.166-67/2001, cuja implementação foi bastante limitada. Apesar de ser um instrumento que, em teoria, possibilita maior eficiência econômica no cumprimento da norma ambiental, seria ingênuo assumir que uma alteração legal levaria a conformidade imediata da lei. $\mathrm{Na}$ realidade, inúmeros desafios e

${ }^{3}$ Ou seja, estimava-se que haviam sido desmatados 43 milhões de hectares de vegetação nativa em desconformidade com a previsão legal de manutenção da Área de Reserva Legal.

${ }^{4}$ SPAROVEK, Gerd, et. al.. Brazilian Agriculture and Environmental Legislation: Status and Future Challenges. Environmental Science and Technology, Vol. 44, 16, 2010. Disponível em: < http://pubs.acs.org/doi/abs/10.1021/es1007824>. Acesso em 19 de fevereiro de 2018.

${ }^{5}$ A proporção da propriedade (ou posse) que deve ser mantida a título de Reserva Legal varia conforme o bioma e região do país: na Amazônia Legal (totalidade dos estados do Acre, Amapá, Amazonas, Mato Grosso, Pará, Rondônia, Roraima e Tocantins e parte do Estado do Maranhão), 80\% no imóvel situado em área de florestas, 35\% no imóvel situado em área de cerrado e $20 \%$ no imóvel situado em área de campos gerais; $20 \%$ nas demais regiões do país.

${ }^{6}$ MAY, Peter, et. al.. Cotas de Reserva Ambiental no Novo Código Florestal Brasileiro: uma avaliação ex-ante. Publicação Ocasional, No. 146, 2015. Disponível em:

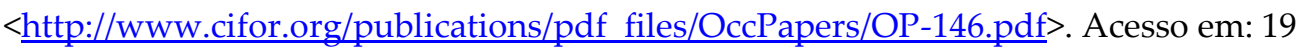
de fevereiro de 2018. 
incertezas podem impedir o bom resultado desse mecanismo de mercado para a gestão ambiental.

A Análise Econômica do Direito (AED) pode ajudar a elucidar, não apenas os fatores, circunstâncias e trade-off existentes quando são tomadas certas decisões de cunho ambiental, mas também a maneira pela qual a ordem jurídica pode contribuir para a obtenção de resultados mais eficientes em políticas que compatibilizem desenvolvimento econômico e preservação ambiental.

Por meio do referencial bibliográfico da AED e da análise da legislação brasileira, o presente trabalho busca identificar possíveis entraves na constituição de um mercado de CRA. Para tanto, o estudo foi dividido em seis seções, incluída essa introdução. A seguir, discorre-se sobre os fundamentos econômicos dos Sistemas de Certificados Negociáveis: tipo de instrumento econômico de gestão ambiental que inspirou a CRA. Depois, examinamos como a nova lei florestal concebe as Cotas de Reserva Ambiental. Na seção IV, foram examinadas as alocações tácitas de direitos de propriedade que o funcionamento desse instrumento implica. E, posteriormente, na seção $\mathrm{V}$, pontuam-se os desafios econômicos e institucionais que se colocam para seu bom desempenho. Por fim, são feitas algumas considerações finais.

\section{Políticas ambientais e Sistemas de Certificados Negociáveis}

Considerando que o meio ambiente influencia na qualidade de vida e que os recursos ambientais são insumos de todos processos produtivos, fica claro que a degradação ambiental pode reduzir o bem-estar social. Consequentemente, se buscamos o máximo bem-estar social alocando eficientemente todos os recursos escassos, aqueles relativos ao meio ambiente devem ser levados em consideração. Contudo, dado as características dos problemas ambientais - diversidade e complexidade, gaps temporais, transbordamentos espaciais, incertezas em relação aos níveis limites de assimilação - os direitos de propriedade relevantes frequentemente são mal definidos e os custos de transação de negociar a compra e venda desses sãos normalmente elevados Tais circunstâncias geram falhas de mercado - mais especificamente, externalidades negativas e positivas que representam perdas e ganhos de bem-estar que 
não são internalizados nos preços de mercado - e justificam a necessidade de regulação ambiental. ${ }^{7}$

Para além dos instrumentos de comando e controle - normas, procedimentos e padrões a serem obedecidos, acompanhados de um conjunto de penalidades - atualmente grande parte dos países instituem também instrumentos econômicos de gestão ambiental, os quais, atuam no sentido de alterar o preço (custo) de utilização de um recurso, internalizando as externalidades e, portanto, afetando seu nível de utilização (demanda). ${ }^{8}$ Conforme Perman et. al., "these instruments alter the structure of pay-offs that agents face". ${ }^{\prime}$

Existem dois grandes grupos de instrumentos econômicos de gestão ambiental. O primeiro são aqueles inspirados pela teoria de Arthur Cecil Pigou, segundo o qual, a correção da externalidade negativa gerada por um dano ambiental (poluição/degradação da qualidade do meio ambiente) poderia ser feita mediante a imposição, pelo Estado, de um tributo, incidente sobre cada unidade produzida, igual à diferença entre o custo marginal privado e o custo marginal social (a mesma lógica se aplicaria na correção de externalidades positivas com a instituição de subsídios). O segundo grupo são aqueles influenciados pelo trabalho de Ronald Coase - The Problem of Social Cost ${ }^{10}$ - que estabelece que, em uma situação de baixos custos de transação ${ }^{11}$ e direitos de propriedade bem definidos, a livre negociação entre indivíduos pode corrigir as externalidades negativas, levando a resultados eficientes. É nesse último grupo que se encontram os Sistemas de Certificados Negociáveis.

Por meio desse instrumento, o Estado estabelece um limite para a quantidade total de poluição permitida - ou seja, não pode haver acréscimos de emissões sem que ocorram decréscimos equivalentes no sistema - compatível com a qualidade ambiental desejada, emite a

${ }^{7}$ ESTY, Daniel. Revitalizing Environmental Federalism. Michigan Law Review, Vol. 95, 3, 1996, p. 570-653.

${ }^{8}$ MOTTA, Ronaldo Seroa da. O Uso de Instrumentos Econômicos na Gestão

Ambiental. Rio de Janeiro, RJ: IPEA, 2000.

9 PERMAN, Roger, et. al.. Natural Resource and Environmental Economics. $3^{\mathrm{a}}$ ed.

Harlow: Pearson Education, 2003, p. 217.

${ }^{10}$ COASE, Ronald. The Problem of Social Cost. Journal of Law and Economics, Vol. 3, $1,1960$.

${ }^{11}$ Segundo Coase, os custos de transação seriam os custos de se recorrer ao mercado nas decisões de produção, ou seja, eles derivariam da utilização do sistema de preços. Cf. COASE, Ronald. The Problem of Social Cost. Journal of Law and Economics, Vol. $3,1,1960$.

3 JOURNAL OF INSTITUTIONAL STUDIES 2 (2017) 
quantidade correspondente de Certificados Negociáveis de Poluição e os distribui entre os agentes poluidores. ${ }^{12}$ A qualidade de serem transferíveis insere um custo de oportunidade na decisão de poluir, nas palavras de Perman et. al., "the firm incurs a cost in emitting each unit of the pollutant, that cost being the current market permit price". ${ }^{13}$

O mercado para os certificados negociáveis se estabelece porque as firmas os valoram de forma diferente em decorrência da existência de distintos custos marginais de abatimento da poluição. Firmas com altos custos de abatimento estarão dispostas a pagar altos preços na compra de certificados, enquanto que aquelas com baixos custos de abatimentos se disporiam a pagar pequenas somas pelos mesmos. Assim sendo, além das firmas que recebem certificados de poluição em excesso, outras podem considerar preferível vender seus certificados (no lugar de comprá-los) se o preço de venda exceder o seu custo marginal de abatimento. No equilíbrio, os custos marginais de abatimento das firmas se igualarão e a meta de poluição será alcançada ao menor custo.

O instrumento de Cotas de Reserva Ambiental instituído pela nova lei florestal não funcionaria exatamente como um Sistema de Certificados Negociáveis de Poluição, uma vez que o que é transacionado não é o direito de impactar, mas a obrigação de preservar. Similarmente, contudo, o poder público determina um nível ótimo de vegetação nativa, distribui (sem custos e de forma arbitrária) as obrigações de Reserva Legal entre os proprietários dos diferentes biomas e permite que proprietários com carência de Reserva Legal comprem daqueles com excesso. $\mathrm{O}$ preço das cotas não seria resultado das diferenças nos custos marginais de abatimento, mas dos diferentes custos de oportunidade da terra. ${ }^{14}$

${ }^{12}$ CÁNEPA, Eugenio. Economia da Poluição. In: Peter May (Org.). Economia do Meio Ambiente: Teoria e Prática. 2aㅡ ed. Rio de Janeiro, RJ: Elsevier, 2010.

${ }^{13}$ PERMAN, Roger, et. al.. Natural Resource and Environmental Economics. $3^{\underline{a}}$ ed. Harlow: Pearson Education, 2003, p. 223.

${ }^{14}$ SANTOS, Laura Meneghel dos; PORTO, Antônio José Maristrello; SAMPAIO, Rômulo Silveira da Rocha. Direitos de Propriedade e Instrumentos Econômicos de Regulação Ambiental: Uma Análise das Atribuições Implícitas. Revista Brasileira de Políticas Públicas, Vol. 7, 2, 2017. Disponível em: $<$ https://www.publicacoesacademicas.uniceub.br/RBPP/article/view/4633/pdf $>$. Acesso em: 19 de fevereiro de 2018. 


\section{O Novo Código e As Cotas De Reserva Ambientais}

O antigo Código Florestal Brasileiro (CFB), instituído pela Lei Federal $\mathrm{n}^{\circ} 4.771 / 1965$, determinava que cada propriedade de terra rural mantivesse parte de sua área total com vegetação nativa, denominada Área de Reserva Legal (ARL), fixando as áreas a serem protegidas de acordo com as regiões. Essa obrigação foi mantida pela atual lei florestal (Lei $n^{0}$ 12.651/12).15 Apesar da importância das reservas legais (e Áreas de Preservação Permanente - APP) ${ }^{16}$ para a proteção e restauração de processos ecológicos essenciais, em virtude da falta de tecnologia ou insumos para a restauração, dos custos de oportunidade e da ausência de aplicação rigorosa do antigo Código Florestal, muitos proprietários de terra optavam por descumprir a lei e acumular passivos ou multas. ${ }^{17}$

O Novo Código Florestal isentou de multa todos os desmatamentos ilegais realizados antes de 22 de julho de 2008, mas exigiu que as propriedades superiores a quatro módulos fiscais ${ }^{18}$ regularizassem sua situação no futuro. ${ }^{19}$ Sendo assim, foram ampliados os mecanismos de

${ }^{15}$ Atualmente, o percentual da propriedade que deve ser registrado como Reserva Legal é: 80\% em propriedades rurais localizadas em área de floresta na Amazônia Legal; 35\% em propriedades situadas em áreas de Cerrado na Amazônia Legal; e 20\% em propriedades situadas em outras formas de vegetação nas demais regiões do país. 16 Áreas de Preservação Permanente (APPs) são definidas como áreas cobertas ou não por vegetação, situadas, por exemplo, ao longo de cursos d'água, ao redor de nascentes, encostas íngremes e áreas em altitude superior a mil e oitocentos metros. Cf. SILVA, Jessica Santos da; RANIERI, Victor Eduardo Lima. O Mecanismo de Compensação de Reserva Legal e suas Implicações Econômicas e Ambientais.

Ambiente \& Sociedade, Vol. 17, 1, 2014.

${ }^{17}$ MAY, Peter, et. al.. Cotas de Reserva Ambiental no Novo Código Florestal Brasileiro: uma avaliação ex-ante. Publicação Ocasional, No. 146, 2015. Disponível em:

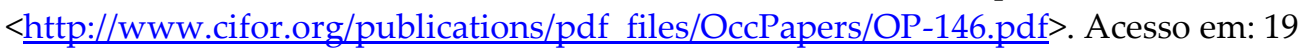
de fevereiro de 2018.

${ }^{18} \mathrm{O}$ módulo fiscal é definido pela área de terra conceitualmente necessária para suprir as necessidades básicas de uma família rural. Tal dimensão é estabelecida pelos estados.

${ }^{19}$ No total, a nova legislação florestal reduziu a área estimada com déficit de RL em $58 \%$, de $50 \pm 6$ a $21 \pm 0,6$ Mha. Cf. MAY, Peter, et. al.. Cotas de Reserva Ambiental no Novo Código Florestal Brasileiro: uma avaliação ex-ante. Publicação Ocasional, No. 146, 2015, p. 2. Disponível em: 
flexibilização da norma com a instituição da Cota de Reserva Ambiental (CRA), pelo artigo 44 da Lei 12.651/2012, que possibilita aos proprietários rurais compensar déficits de ARL em uma propriedade com excedentes de ARL de outras propriedades dentro do mesmo bioma. Segundo Milaré e Machado $^{20}$, as cotas de reserva ambiental consistem em títulos representativos, os quais não representam uma verdadeira operação de crédito, mas sim de mercadorias ou bens que fundamentam sua existência. Para que fosse possível o estabelecimento desse sistema, a nova legislação criou o Cadastro Ambiental Rural (CAR):

Exige que todos os proprietários ou posseiros de propriedades rurais registrem suas terras no órgão ambiental estadual, delineando a RL e a APP georreferenciadas em imagens de satélite (...) para servir de base para o monitoramento do cumprimento. Para fins de conformidade ambiental, o CAR (...) e outras exigências do Código Florestal se aplicam a todas as propriedades rurais (e podem ser referidos como critérios para concessão de empréstimos por fontes de crédito ou como critérios de aquisição por frigoríficos ou outros compradores privados de commodities agrícolas). Embora o CAR seja obrigatório para todos os tipos de propriedade, a emissão de CRA é aberta apenas aos proprietários de terras tituladas. ${ }^{21}$

Segundo o artigo 66 da nova lei florestal, o proprietário de imóvel rural que detinha, em 22 de julho de 2008, uma área de Reserva Legal em inferior à sua obrigação legal pode regularizar sua situação de três formas: recompor a $\mathrm{ARL}^{22}$, permitir a regeneração natural da vegetação na área de ARL ou compensar a ARL. Tal compensação pode ocorrer de quatro formas: i) aquisição de CRAs; ii) arrendamento de área sob regime

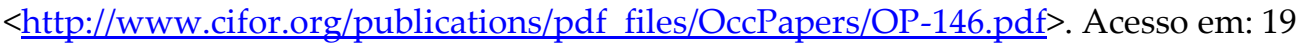
de fevereiro de 2018.

${ }^{20}$ MILARÉ, Édis; MACHADO, Paulo Affonso Leme (Orgs.). Novo Código Florestal

Comentado: Comentários à Lei no ${ }^{0}$ 12.651, de 25 de maio de 2012, à Lei $\mathbf{n}^{\mathrm{o}}$ 12.727, de 17 de outubro de 2012 e ao Decreto no 7830 , de 17 de outubro de 2012. $2^{\text {a }}$ ed. São Paulo, SP: Revista dos Tribunais, 2013.

${ }^{21}$ MAY, Peter, et. al.. Cotas de Reserva Ambiental no Novo Código Florestal Brasileiro: uma avaliação ex-ante. Publicação Ocasional, No. 146, 2015. Disponível em:

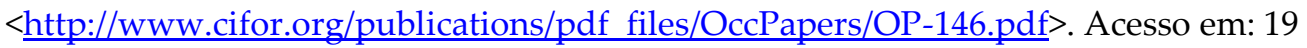
de fevereiro de 2018.

${ }^{22}$ A recomposição deverá atender os critérios estipulados pelo órgão competente do Sisnama e ser concluída em até 20 anos, abrangendo, a cada 2 anos, no mínimo 1/10 da área total necessária à sua complementação (Lei 12.651/2012, art.66, §ºํ). 
de servidão ambiental; iii) doação ao poder público de área localizada no interior de Unidade de Conservação de domínio público pendente de regularização fundiária; ou iv) cadastramento de outra área equivalente e excedente à RL em imóvel de mesma titularidade ou adquirida em imóvel de terceiro, com vegetação nativa, em regeneração ou recomposição, desde que localizada no mesmo bioma e estado.

As áreas a serem utilizadas para compensação devem ser equivalentes em extensão à área da Reserva Legal a ser compensada; estar localizadas no mesmo bioma da área de Reserva Legal a ser compensada; e, quando estiver localizada fora do Estado, ser identificada como áreas prioritárias pela União ou pelos Estados - para favorecer a recuperação de bacias hidrográficas excessivamente desmatadas, a criação de corredores ecológicos, a conservação de grandes áreas protegidas e a conservação ou recuperação de ecossistemas ou espécies ameaçados.

Dentre as especificidades das transações de Cotas de Reserva Ambiental, destaca-se que:

- Somente os déficits de ARL feitos antes de 22 de julho de 2008 podem ser compensados por meio da compra de CRA ${ }^{23}$;

- Não se admite, para fins de emissão de CRA, que a área contenha vegetação não classificada como nativa;

- É obrigatório o registro da CRA pelo órgão ambiental emitente, no prazo de 30 (trinta) dias da data da sua emissão, em bolsas de mercadorias de âmbito nacional ou em sistemas de registro e de liquidação financeira de ativos autorizados pelo Banco Central do Brasil.

- A CRA pode ser transferida, onerosa ou gratuitamente, a pessoa física ou a pessoa jurídica de direito público ou privado, mediante termo assinado pelo titular da CRA e pelo adquirente.

${ }^{23}$ Depois de 22 de julho de 2008, todos os proprietários de terras que diminuam sua vegetação nativa acima dos limites legais permitidos deverão retornar para a legalidade pela restauração dessas áreas, sem possibilidade de comprar CRA, ou seja, "as CRA são apenas um instrumento para auxiliar o cumprimento de déficits históricos (e não de futuros". MAY, Peter, et. al.. Cotas de Reserva Ambiental no Novo Código Florestal Brasileiro: uma avaliação ex-ante. Publicação Ocasional, No. 146, 2015, p. 3. Disponível em:

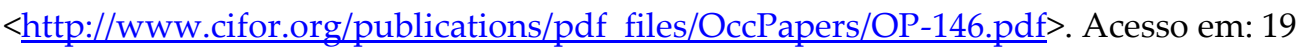
de fevereiro de 2018. 
- A transferência da CRA só produz efeito uma vez registrado o termo acima mencionado no sistema único de controle ${ }^{24}$;

- Cabe ao proprietário do imóvel rural em que se situa a área vinculada à CRA a responsabilidade plena pela manutenção das condições de conservação da vegetação nativa da área que deu origem ao título;

- A transmissão inter vivos ou causa mortis do imóvel não elimina nem altera o vínculo de área contida no imóvel à CRA;

- A CRA poderá ser cancelada ${ }^{25}$ somente nos seguintes casos:

- automaticamente, observado o término do prazo de servidão ambiental (conforme os acréscimos feitos pelo Novo Código Florestal, a servidão pode ser perpétua ou temporária, sendo que neste caso estabelece-se o prazo mínimo de 15 anos);

- por solicitação do proprietário rural, em caso de desistência de manter áreas nas condições previstas;

- por decisão do órgão competente do Sistema Nacional do Meio Ambiente (Sisnama), no caso da degradação da vegetação nativa da área vinculada à CRA inviabilizar a continuidade do vínculo entre a área e o título.

Cabe ainda mencionar que a atual legislação prevê a possibilidade de entidades credenciadas (fora o órgão ambiental) realizarem a emissão de laudo comprobatório da existência de áreas passíveis de gerarem CRA, ou seja, atestando a presença de vegetação nativa ou em processo de recuperação para além das exigências legais aplicáveis. Conforme destaca Machado, apesar de isso evitar a oneração dos órgãos ambientais, já sobrecarregados, "o credenciamento propriamente dito carece de

${ }^{24}$ Nesta etapa, é prevista, ainda, uma nova checagem de dados para assegurar que: i) aquela determinada CRA está sendo pleiteada para compensação de área situada no mesmo bioma; ii) se fora do estado da área cedente, a cessionária encontra-se localizadas em áreas identificadas como prioritárias pela União ou pelos estados; e iii) se as áreas são equivalentes em extensão. Cf. MACHADO, Lourdes de Alcantara. O Cadastro Ambiental Rural e as Cotas de Reserva Ambiental no Novo Código Florestal: uma análise de aspectos legais essenciais para a sua implementação. In: Ana Paula Moreira da Silva; Henrique Rodrigues Marques; Regina Helena Rosa Sambuichi (Org.). Mudanças no Código Florestal Brasileiro: Desafios para a Implementação da Nova Lei. Rio de Janeiro, RJ: Ipea/IPC-IG, 2016, p. 64.

25 “O cancelamento da CRA utilizada para fins de compensação de Reserva Legal só pode ser efetivado se assegurada Reserva Legal para o imóvel no qual a compensação foi aplicada". (Lei 12.651/2012, art. 50, §1 ${ }^{\circ}$ ). 
regulamentação específica, à semelhança de outras etapas do processo de emissão e utilização das CRAs". ${ }^{26}$

\section{DIREITOS DE PROPRIEDADE NO MERCADO DE CRA}

Para $\mathrm{Cole}^{27}$, todas formas de regulação ambiental refletem propertybased solutions para a tragédia dos comuns ${ }^{28}$, que pode ser entendida como a superexploração dos recursos naturais. Nessa linha, o problema da política ambiental pode ser visto como uma disputa sobre quem terá o controle dos fluxos futuros de serviços ambientais. ${ }^{29}$ Diferentes políticas ambientais refletiriam arranjos institucionais diversos, conforme apontado por Louis Alessi:

Institutions establish how individuals are permitted to benefit and harm themselves and others. Institutions perform this function by specifying the rights that individuals may hold to the use of resources, to the stream of services (income or utility) that the resources yield, and to the transferability of these rights to others. ${ }^{30}$

${ }^{26}$ MACHADO, Lourdes de Alcantara. O Cadastro Ambiental Rural e as Cotas de Reserva Ambiental no Novo Código Florestal: uma análise de aspectos legais essenciais para a sua implementação. In: Ana Paula Moreira da Silva; Henrique Rodrigues Marques; Regina Helena Rosa Sambuichi (Org.). Mudanças no Código Florestal Brasileiro: Desafios para a Implementação da Nova Lei. Rio de Janeiro, RJ: Ipea/IPC-IG, 2016, p. 62.

${ }^{27}$ COLE, Daniel. New Forms of Private Property: Property Rights in Environmental Goods. In: Boudewijn Bouckaert (ed.). Encyclopedia of Law and Economics, Vol. 5: Property Law and Economics. $2^{a}$ ed. Northampton, MA: Edward Elgar Publishing, 2010, p. 9.

${ }^{28}$ HARDIN, Garret. The Tragedy of the Commons. Science, Vol. 162, 3859, 1968, p. 1243-1248.

${ }^{29}$ BROMLEY, Daniel. Environment and Economy: Property Rights and Public

Policy. Oxford: Basil Blackwell, 1991, p. 38 (tradução livre).

${ }^{30}$ DE ALESSI, Louis. Private Property Rights as the Basis for Free Market

Environmentalism. In: Peter Hill; Roger Meiners (eds.). Who Owns the Environment? Lanham, MD: Rowman \& Littlefield Publishers, 1998, p. 6. 
A estrutura analítica de direitos de propriedade proposta por Elinor Ostrom $^{31}$ contribui para um maior esclarecimento acerca do objeto de transação no mercado de CRA. A autora, ao analisar a forma de gestão dos recursos comuns - aqueles bens não exclusivos e rivais - define direitos de propriedade como ações (referentes a alguma coisa) que os indivíduos podem tomar em relação a outros indivíduos. Então, considerando a propriedade como feixe de direitos, a autora identifica cinco tipos de direitos de propriedade relevantes para a gestão dos recursos comuns ${ }^{32}$ :

- Acesso (direito operacional): $\mathrm{O}$ direito de entrar em uma área física definida e desfrutar benefícios não subtrativos;

- Exploração (direito operacional): O direito de obter unidades de recursos ou produtos de um sistema de recursos;

- Administração (direito de escolha coletiva): O direito de regular padrões de uso interno e transformar o sistema de recursos por meio de melhorias;

- Exclusão (direito de escolha coletiva): O direito de determinar quem terá os direitos de acesso e de exploração e como esses direitos podem ser transferidos;

- Alienação (direito de escolha coletiva): O direito de vender ou transferir os direitos de administração e exclusão.

É importante destacar que indivíduos (ou coletividades) podem possuir direitos de propriedade bem definidos que incluem ou não todos

${ }^{31}$ OSTROM, Elinor; HESS, Charlotte. Private and Common Property Rights. In: Boudewijn Bouckaert (ed.). Encyclopedia of Law and Economics, Vol. 5: Property Law and Economics. 2 ${ }^{\mathrm{a}}$ ed. Northampton, MA: Edward Elgar Publishing, 2010. ${ }^{32}$ De forma geral, os recursos ambientais, definidos pelo art. $3^{\circ}$, inc. V, da Lei 6.938/81, como sendo a atmosfera, as águas interiores, superficiais e subterrâneas, os estuários, o mar territorial, o solo, o subsolo, os elementos da biosfera, a fauna e a flora, podem ser considerados recursos comuns. Cf. SANTOS, Laura Meneghel dos; PORTO, Antônio José Maristrello; SAMPAIO, Rômulo Silveira da Rocha. Direitos de Propriedade e Instrumentos Econômicos de Regulação Ambiental: Uma Análise das Atribuições Implícitas. Revista Brasileira de Políticas Públicas, Vol. 7, 2, 2017. Disponível em: $<$ https://www.publicacoesacademicas.uniceub.br/RBPP/article/view/4633/pdf $>$. Acesso em: 19 de fevereiro de 2018. 
os direitos acima descritos. Ou seja, para Ostrom $^{33}$ direitos de propriedade bem definidos não se resumem à possibilidade de alienação.

Olhando para o mercado de CRA com base no feixe de direitos estabelecidos por Ostrom, podemos considerar que é atribuído à sociedade um direito operacional de acesso aos benefícios ambientais (direito difuso) associados às ARL. À autoridade central, por sua vez, pertence os direitos de administração e exclusão, uma vez que ela decide o nível ótimo de vegetação nativa de cada bioma, determina a parcela atribuída a cada proprietário rural e quem pode transacionar essas obrigações de preservação. O que é transacionado pelos proprietários é somente um direito de exploração, nesse caso, o direito de promover outros usos da terra resultante da transferência do dever conservacionista (obviamente dentro dos limites estabelecidos).

O trabalho seminal de Calabresi e Melamed $^{34}$ nos fornece outra perspectiva para a análise das CRA. Segundo a estrutura analítica desenvolvida pelos autores, em qualquer disputa legal, além de decidir o lado vencedor - ou a quem pertence o direito - o Estado deve também estabelecer qual o tipo de proteção que será concedida, os autores identificam três tipos de direitos: aqueles protegidos por regras de propriedade (property rules), aqueles protegidos por regras de responsabilidade (liability rules) e direitos inalienáveis. Conforme apontam "the categories are not, of course, absolutely distinct; but the categorization is useful since it reveals some of the reasons which lead us to protect certain entitlements in certain ways". ${ }^{35}$

Um direito protegido por uma regra de propriedade só pode ser removido de seu titular a partir de uma transação voluntária, sendo seu valor negociado entre comprador e vendedor. Esta seria a forma de proteção que demandaria menor intervenção estatal, uma vez que, após determinar a alocação do direito, o Estado não tenta determinar seu valor.

A regra da responsabilidade (liability rule) estabelece que a parte desfavorecida pode forçar a parte favorecida a ceder-lhe o direito ao pagar uma quantia em dinheiro fixada pelo juiz ou por outro funcionário

${ }^{33}$ OSTROM, Elinor; HESS, Charlotte. Private and Common Property Rights. In: Boudewijn Bouckaert (ed.). Encyclopedia of Law and Economics, Vol. 5: Property Law and Economics. 2ª ed. Northampton, MA: Edward Elgar Publishing, 2010. ${ }^{34}$ CALABRESI, Guido; MELAMED, Douglas. Property Rules, Liability Rules, and Inalienability: One View of the Cathedral. Harvard Law Review, Vol. 85, 6, 1972. ${ }^{35}$ CALABRESI, Guido; MELAMED, Douglas. Property Rules, Liability Rules, and Inalienability: One View of the Cathedral. Harvard Law Review, Vol. 85, 6, 1972, p. 1092. 
do governo. Obviamente, aqui uma maior intervenção do Estado é demandada, dado que "not only are entitlements protected, but their transfer or destruction is allowed on the basis of a value determined by some organ of the state rather than by the parties themselves". ${ }^{36}$

Por fim, os direitos são inalienáveis quando sua transferência não é permitida mesmo que existam compradores e vendedores dispostos a negocia-lo. O Estado intervém proibindo a venda do direito em algumas ou todas as circunstâncias. Assim, as regras de inalienabilidade podem ser vistas como limitantes ou regulamentações da concessão do próprio direito. ${ }^{37}$

A partir da perspectiva proposta por Calabresi e Melamed, podemos assumir que, com o estabelecimento das CRAs, foram criados dois direitos em relação ao meio ambiente. Por um lado, a sociedade recebe um direito inalienável aos serviços ambientais prestados pela conservação das florestas (o nível ótimo foi estabelecido pela autoridade central). Por outro lado, através das CRAs, alguns proprietários de terras recebem obrigações de preservação protegidas por uma regra de propriedade cujo preço é o resultado de uma negociação entre comprador e vendedor (o que provavelmente leva em conta os custos de oportunidade de suas terras).

\section{DESAFIOS PARA IMPLEMENTAÇÃO}

O primeiro desafio a ser enfrentado no estabelecimento do mercado de CRA é identificar quais proprietários possuem déficits e quais possuem superávits de ARL. ${ }^{38}$ Mais especificamente, é necessário identificar os limites das propriedades das partes interessadas (quem possui o direito àquelas terras) e a proporção da área de vegetação nativa em cada imóvel rural. O Sistema de Cadastro Rural Ambiental (SICAR) -

${ }^{36}$ CALABRESI, Guido; MELAMED, Douglas. Property Rules, Liability Rules, and Inalienability: One View of the Cathedral. Harvard Law Review, Vol. 85, 6, 1972, p. 1092.

${ }^{37}$ CALABRESI, Guido; MELAMED, Douglas. Property Rules, Liability Rules, and Inalienability: One View of the Cathedral. Harvard Law Review, Vol. 85, 6, 1972, p. 1093.

${ }^{38}$ Os proprietários rurais possuem incentivos para declararem ARL em excesso, visto que a constatação de déficits de ARL significa incorrer em custos no futuro. Logo a determinação da situação real da ARL da propriedade se torna um desafio frente as dimensões continentais do Brasil. 
sistema georreferenciado baseado na internet - visa enfrentar esse obstáculo, permitindo o cadastro de mais de 5 milhões de propriedades rurais e calculando automaticamente os passivos legais a partir do carregamento dos limites georreferenciados das propriedades e demarcação dos corpos d'água e remanescentes florestais.

Contudo, a primeira fase do cadastramento (ainda em aberto) é auto declaratória, ou seja, os próprios proprietários informam os limites de suas propriedades; isso resultou, em alguns estados, principalmente aqueles das regiões Norte ${ }^{39}$ e Sudeste, numa área cadastrada superior a área total passível de cadastro. Assim sendo, provavelmente será necessário recorrer a esfera judiciária para a resolução desses conflitos e sobreposições. É importante salientar que esses custos de transação especificamente relacionados a delimitação dos imóveis rurais (ou seja, a definição de direitos de propriedade para verificar quem possui excesso e quem possui déficit de ARL) não podem ser atribuídos unicamente, nem principalmente, ao mercado de CRA, dado que o cadastramento é um elemento central da nova legislação florestal (que inclui, mas não se restringe às $\mathrm{CRA}$ ).

Conforme apontado inicialmente, diferentes custos de oportunidade da terra fazem com que seja mais barato conservar ou restaurar florestas em áreas com rendimentos agrícolas mais baixos do que em áreas de valor agrícola mais alto. Logo, a possibilidade de transacionar CRA promoveria ganhos de eficiência econômica ao permitir a regularização dos déficits de ARL (em áreas de alta produtividade agrícola) com custos menores (ou seja, em áreas com produtividade agrícola relativamente menor). No entanto, para que um mercado de CRA seja estabelecido e funcione de maneira adequada, é fundamental que os custos associados a essas transações sejam baixos.

Mesmo que a questão dos limites dos estabelecimentos rurais mencionada anteriormente tivesse sido resolvida, a partir da reflexão pioneira proposta por Ronald Coase, é possível admitir a existência de outros custos $^{40}$ capazes de eliminar os ganhos de eficiência

${ }^{39}$ No Amazonas, por exemplo, a área total cadastrada é de 23.828 .608 ha, bastante superior a área passível de cadastro de 6.733 .964 ha, conforme o Boletim Informativo do CAR de Outubro de 2016. Disponível em: $<$ http://www.florestal.gov.br/cadastroambiental-rural/numeros-do-cadastro-ambiental-rural >. Acesso em: 23 de novembro de 2016.

${ }^{40}$ Nesse trabalho não se compartilha da concepção de Douglas Allen, para quem custos de transação são os custos de estabelecer e manter direitos de propriedade. Para esse autor, diferentemente da proposição de Coase, seria inconcebível uma 
proporcionados pelo uso desse instrumento econômico de gestão ambiental:

In order to carry out a market transaction it is necessary to discover who it is that one wishes to deal with, to inform people that one wishes to deal and on what terms, to conduct negotiations leading up to a bargain, to draw up the contract, to undertake the inspection needed to make sure that the terms of the contract are being observed, and so on. These operations are often extremely costly. ${ }^{41}$

Ademais, a implementação das CRA (e o funcionamento desse mercado) dependerá do avanço do Cadastro Ambiental Rural (CAR) e das legislações adicionais que surgirem para viabilizar esse instrumento nos estados. Conforme apontam May et. al. ${ }^{42}$, a complexidade institucional das regras para o registro de terras disponíveis para a negociação de CRA poderia adicionar múltiplas camadas de custos de transação a esse mecanismo. Para Britaldo Soares-Filho ${ }^{43}$, a viabilidade de monitoramento e fiscalização entre propriedades distantes também poderia prejudicar a eficiência do instrumento.

O uso da Teoria dos Jogos pode nos ajudar a compreender melhor de que maneira a fiscalização do cumprimento das ARL pode afetar as

situação em que os direitos de propriedade são bem definidos e assegurados e custos de transação significantes, dado que ele parece acreditar que direitos de propriedade mal definidos, mal atribuídos e mal garantidos são a única fonte de custos de transação. Retomando as reflexões de Douglas North e Yoram Barzel, Fiani assinala que "direitos de propriedade multidimensionais em um mundo de custos de transação positivos serão sempre mal definidos, nunca totalmente garantidos de forma antecipada", ou seja, a direção e o sentido da causalidade não seriam unilaterais. FIANI, Ronaldo. Cooperação e Conflito: Instituições e Desenvolvimento Econômico. Rio de Janeiro, RJ: Elsevier, 2011.

${ }^{41}$ COASE, Ronald. The Firm, the Market, and the Law. Chicago, IL: University of Chicago Press, 1988, p. 114.

${ }^{42}$ MAY, Peter, et. al.. Cotas de Reserva Ambiental no Novo Código Florestal Brasileiro: uma avaliação ex-ante. Publicação Ocasional, No. 146, 2015, p. 4. Disponível em: $<$ http://www.cifor.org/publications/pdf files/OccPapers/OP-146.pdf $>$. Acesso em: 19 de fevereiro de 2018.

${ }^{43}$ MAY, Peter, et. al.. Cotas de Reserva Ambiental no Novo Código Florestal Brasileiro: uma avaliação ex-ante. Publicação Ocasional, No. 146, 2015, p. 24. Disponível em:

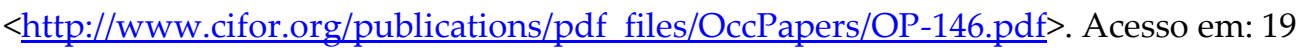
de fevereiro de 2018. 
decisões estratégicas dos compradores e vendedores de CRA. O Jogo é a situação hipotética em que dois participantes de uma interação, os chamados jogadores ou agentes, tomam decisões que levem em consideração as atitudes e as respostas do outro. Ao final de uma interação, cada jogador recebe uma recompensa (payoff), resultado de uma estratégia ótima que busca maximizar a recompensa esperada de cada um. O jogo fornece uma representação simplificada e subjetiva da realidade, tendo um conjunto de regras explícitas.

Para uma mera ilustração, em nosso exemplo consideramos um jogo simultâneo (onde as decisões dos jogadores são tomadas ao mesmo tempo), com informação completa - ou seja, a matriz dos payoffs é conhecida por todos jogadores que são agentes econômicos racionais. Estamos interessados em encontrar o equilíbrio de Nash, resultante da melhor estratégia individual de cada agente. Aqui, consideramos dois cenários onde a assinatura do termo de transferência de CRA não gera custos de transação: 1) sem fiscalização dos termos de transferência de CRA; 2) com fiscalização e possibilidade de punição por descumprimento. Um jogador é o comprador da CRA e o outro é o vendedor.

No primeiro cenário, quando o comprador cumpre o que foi estabelecido no termo, pagando pela preservação nas terras do vendedor, sua recompensa é o que ele recebe pela exploração econômica daquela área (ou o custo de oportunidade da terra, $\mathrm{Cot}^{\prime}$ ) menos o que ele pagou pelas CRA (Vcra); caso o comprador não cumpra o estabelecido no termo, não realizando o pagamento da CRA, seu payoff é custo de oportunidade da terra não destinada a ARL. Quando o vendedor da CRA cumpre o termo e o comprador também, sua recompensa é o valor recebido pela CRA; se o comprador não respeitar o acordo estabelecido, o vendedor perde o que ele poderia ter ganho com a exploração econômica daquela terra $\left(\operatorname{Cot}^{\prime \prime}\right)$ caso se mantenha fiel ao termo. Se o contrário ocorrer, o comprador respeita o termo e o vendedor não, o payoff deste é o que ele ganha com a exploração econômica daquela área ( $\left.\operatorname{Cot}^{\prime \prime}\right)$ mais o que o ele recebe pela venda da CRA (Vcra). Se ambos desrespeitam o termo, ambos usufruem do custo de oportunidade de suas terras, de modo que temos:

\begin{tabular}{|c|c|c|c|}
\hline \multicolumn{2}{|c|}{ Cenário $1\left(\operatorname{Cot}^{\prime}>\right.$ Vcra $\left.>\operatorname{Cot}^{\prime \prime}\right)$} & \multicolumn{2}{c|}{ Comprador da CRA } \\
\cline { 3 - 4 } & Cumpre o termo & Não cumpre o termo \\
\hline $\begin{array}{c}\text { Vendedor } \\
\text { da CRA }\end{array}$ & Cumpre o termo & Vcra; Cot' - Vcra & (-) Cot"; Cot' \\
\hline
\end{tabular}




\begin{tabular}{|c|c|c|}
$\begin{array}{c}\text { Não cumpre o } \\
\text { termo }\end{array}$ & $\begin{array}{c}\text { Vcra + Cot"; Cot'- } \\
\text { Vcra }\end{array}$ & ${\text { Cot"; } \operatorname{Cot}^{\prime}}$ \\
\hline
\end{tabular}

Onde:

Vcra = é o valor recebido (ou pago) em uma transferência de CRA;

$\mathrm{Cot}^{\prime}=$ é o custo oportunidade da terra do comprador da CRA (ou seja, o valor que ele consegue usufruir por não precisar preservar aquela área como ARL);

Cot" $^{\prime \prime}$ = é o custo de oportunidade da terra do vendedor da CRA, ou seja, a área com vegetação nativa (presente ou em processo de formação) que dá origem a CRA.

Nesse cenário, o Equilíbrio de Nash é a situação em que nem o vendedor, nem o comprador respeitam o termo de transferência de CRA. Sem fiscalização, portanto, os jogadores não possuiriam incentivos suficientes para respeitar o termo de transferência de CRA e os objetivos de preservação desejáveis não seriam alcançados. No cenário 2, com fiscalização e possibilidade de punição por descumprimento, teríamos o seguinte jogo:

\begin{tabular}{|c|c|c|c|}
\hline \multirow{2}{*}{\multicolumn{2}{|c|}{ Cenário $2\left(\operatorname{Cot}^{\prime}>\right.$ Vcra $\left.>\operatorname{Cot}^{\prime \prime}\right)$}} & \multicolumn{2}{|c|}{ Comprador da CRA } \\
\hline & & Cumpre o termo & Não cumpre o termo \\
\hline \multirow{2}{*}{$\begin{array}{c}\text { Vendedor } \\
\text { da CRA }\end{array}$} & $\begin{array}{l}\text { Cumpre o } \\
\text { termo }\end{array}$ & Vcra; Cot' - Vcra & (-) $\operatorname{Cot}^{\prime \prime} ; \operatorname{Cot}^{\prime}-\mathrm{Pp}^{\prime} \mathrm{Vp}^{\prime}$ \\
\hline & $\begin{array}{c}\text { Não cumpre o } \\
\text { termo }\end{array}$ & 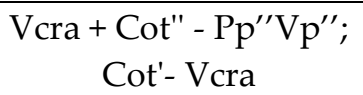 & $\begin{array}{c}\text { Cot" - } \mathrm{Pp}^{\prime \prime} \mathrm{Vp}^{\prime \prime} ; \operatorname{Cot}^{\prime}- \\
\mathrm{Pp} \mathrm{p}^{\prime} \mathrm{Vp}^{\prime}\end{array}$ \\
\hline
\end{tabular}

Onde:

$\mathrm{Pp}^{\prime}=$ é a probabilidade de punição do comprador pelo descumprimento do termo de transferência da CRA;

$\mathrm{Vp}^{\prime}$ = é o valor da punição do comprador pelo descumprimento do termo.

$\mathrm{Pp}^{\prime \prime}=$ é a probabilidade de punição do vendedor pelo descumprimento do termo;

$\mathrm{Vp}^{\prime \prime}=$ é o valor da punição do vendedor pelo descumprimento do termo. 
Nesse cenário, a estratégia vencedora (aquela que maximiza o payoff) do comprador dependerá da relação entre o valor pago com a compra de CRAs e o produto da probabilidade de punição do comprador e o valor de sua punição pelo descumprimento. Por outro lado, a estratégia vencedora do vendedor dependerá da relação entre o custo de oportunidade da terra que pode originar a CRA e o produto da probabilidade de punição do vendedor e o valor de sua punição pelo descumprimento. Ou seja, para incentivar o cumprimento dos termos de transferências de CRA, a autoridade governamental deve estabelecer níveis adequados de fiscalização das ARL e sanções relevantes em caso de descumprimento.

Por fim, a experiência internacional com instrumentos similares de gestão ambiental, mais especificamente, os Transferable Development Rights (TDR) americanos, podem contribuir para compreensão ampliada acerca das circunstancias que contribuem ou obstaculizam o bom desempenho desse mecanismo. Machemer e Kaplowitz ${ }^{44}$, buscando identificar os elementos programáticos para o sucesso dessas iniciativas, testaram algumas hipóteses com base no exame de três experiências diferentes. A análise deles revelou que um alto grau de conhecimento local das demandas e padrões de uso do solo, liderança política e presença de um banco ${ }^{45}$ de TDR são importantes para o sucesso do desses programas. Em estudo posterior ${ }^{46}$, feito com por meio da aplicação de questionários aos gestores locais, outros fatores também se mostraram

${ }^{44}$ MACHEMER, Patricia; KAPLOWITZ, Michael. A Framework for Evaluating Transferable Development Rights Programmes. Journal of Environmental Planning and Management, Vol. 45, 6, 2002, p. 773-795.

${ }^{45}$ Os bancos de TDR podem desempenhar várias funções importantes que contribuem positivamente para o desenvolvimento e eficiência desses mercados, incluindo a compra e venda do TDR, atuação como intermediário ou comprador de última instância e fortalecimento da credibilidade do programa junto às instituições bancárias.

${ }^{46}$ KAPLOWITZ, Michael; MACHEMER, Patricia; PRUETZ, Rick. Planners' Experiences In Managing Growth Using Transferable Development Rights (TDR) in the United States. Land Use Policy, Vol. 25, 3, 2008. 
relevantes, tais como: a associação com programas de PDR ${ }^{47}$ (Purchase of Development Rights) ${ }^{48}$ e a utilização de estudos prévios.

Nessa mesma linha, ao analisar a experiência norte-americana com Tranferable Rights Programs, Tripp e Dudek ${ }^{49}$ listam 8 diretrizes institucionais para o sucesso desse tipo de programa que se aproxima das transações de CRA. Dessa lista, três orientações merecem atenção:

1) A agência responsável pelo programa deve ter capacidade técnica para planeja-lo e implementá-lo. No caso das CRA, isso nos leva a questionar se haverá recursos disponíveis para a preservação no um contexto de crise financeira da União e dos estados.

2) Os direitos negociáveis devem ter valor econômico, ou seja, a demanda por eles deve superar a oferta dos mesmos. Isso pode se tornar problemático no caso das CRA, dado que algumas simulações iniciais (mencionadas por May et. al..$^{50}$ ) apontam que a excessiva permissividade do Novo Código Florestal resultou em um sistema com excesso significativo de oferta de CRA frente a demanda reduzida.

3) Para assegurar o valor econômico dos direitos negociáveis, a compra e venda deve implicar em custos de transação mínimos. Ainda que os custos de fiscalização e monitoramento recaia nos órgãos públicos ou certificadores, vendedores e compradores deveriam acessar o mercado facilmente, o que se configura um grande desafio em um país da dimensão do Brasil. Nesse sentido, a Bolsa Verde do Rio de Janeiro (BVRio) se propôs a mediar as negociações por meio de

\footnotetext{
${ }^{47}$ Relativamente aos programas de PDR, o financiamento geralmente provém de tranferâncias governamentais ou arrecadação de impostos e os direitos de desenvolvimento não são transferidos mas apenas retirados (semelhantemente à alguns programas de Pagamentos por Serviços Ambientais).

48 "TDR and PDR (or other easement purchase programs) are complementary programs; the former allows the market to decide what parcels to preserve, while the latter allows communities to target specific parcels for preservation". MACHEMER, Patricia; KAPLOWITZ, Michael. A Framework for Evaluating Transferable Development Rights Programmes. Journal of Environmental Planning and Management, Vol. 45, 6, 2002, p. 790.

49 TRIPP, James; DUDEK, Daniel. Institutional Guidelines for Designing Successful Transferable Rights Programs. Yale Journal on Regulation, Vol. 6, 2, 1989, p. 369.

${ }^{50}$ MAY, Peter, et. al.. Cotas de Reserva Ambiental no Novo Código Florestal Brasileiro: uma avaliação ex-ante. Publicação Ocasional, No. 146, 2015. Disponível em:

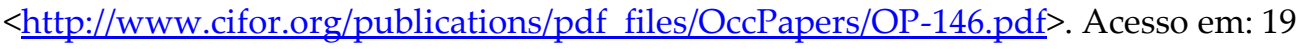
de fevereiro de 2018.
} 
uma plataforma online ${ }^{51}$. Mas, caso haja um excesso de requisitos para participação como ofertante ou demandante, os altos custos de transação poderiam inviabilizar o mercado de CRA.

\section{CONSIDERAÇÕES FINAIS}

O sistema de CRA, sendo um tipo de sistema de certificados negociáveis, tem o potencial de promover o alcance das metas ambientais - em termos de Áreas de Reserva Legal - de forma eficiente, ou seja, transferindo a obrigação de preservar para quem pode fazê-lo com custos mais baixos.

No entanto, para que isso aconteça, os direitos de propriedade devem estar bem definidos e protegidos e os custos de transação devem ser baixos. Tais condições geralmente não existem no mundo real, especialmente em países em desenvolvimento como o Brasil. Além disso, para o sucesso deste instrumento, é essencial que as instituições governamentais estejam bem equipadas para impor a norma ambiental, outro ponto cuja materialização parece distante no país.

O maior uso de instrumentos econômicos para gestão ambiental no Novo Código Florestal Brasileiro representa um importante avanço na promoção da preservação ambiental com eficiência econômica.

No entanto, para que tais mecanismos atinjam essas expectativas, é essencial verificar se as condições institucionais para o sucesso estão presentes. Nesse sentido, parece que a nova legislação florestal não considerou adequadamente o contexto de implementação real desse tipo de política.

Em um cenário de maior escassez de recursos naturais, de crescimento do desmatamento na Amazônia e de cortes nos gastos do governo, são necessários estudos que forneçam mais subsídios para políticas ambientais eficazes.

${ }^{51}$ Disponível em: <http://www.bvrio.org/>. Acesso em: 19 de fevereiro de 2018. 


\section{REFERÊNCIAS}

BROMLEY, Daniel. Environment and Economy: Property Rights and Public Policy. Oxford: Basil Blackwell, 1991.

CÁNEPA, Eugenio. Economia da Poluição. In: Peter May (Org.).

Economia do Meio Ambiente: Teoria e Prática. $2^{a}$ ed. Rio de Janeiro, RJ: Elsevier, 2010.

CALABRESI, Guido; MELAMED, Douglas. Property Rules, Liability Rules, and Inalienability: One View of the Cathedral. Harvard Law Review, Vol. 85, 6, 1972.

COASE, Ronald. The Firm, the Market, and the Law. Chicago, IL: University of Chicago Press, 1988.

3, 1, 1960 .

. The Problem of Social Cost. Journal of Law and Economics, Vol.

COLE, Daniel. New Forms of Private Property: Property Rights in Environmental Goods. In: Boudewijn Bouckaert (ed.). Encyclopedia of Law and Economics, Vol. 5: Property Law and Economics. $2^{\mathrm{a}} \mathrm{ed}$. Northampton, MA: Edward Elgar Publishing, 2010.

DE ALESSI, Louis. Private Property Rights as the Basis for Free Market Environmentalism. In: Peter Hill; Roger Meiners (eds.). Who Owns the Environment? Lanham, MD: Rowman \& Littlefield Publishers, 1998.

ESTY, Daniel. Revitalizing Environmental Federalism. Michigan Law Review, Vol. 95, 3, 1996. 
FIANI, Ronaldo. Cooperação e Conflito: Instituições e

Desenvolvimento Econômico. Rio de Janeiro, RJ: Elsevier, 2011.

HARDIN, Garret. The Tragedy of the Commons. Science, Vol. 162, 3859, 1968.

KAPLOWITZ, Michael; MACHEMER, Patricia; PRUETZ, Rick. Planners' Experiences In Managing Growth Using Transferable Development Rights (TDR) in the United States. Land Use Policy, Vol. 25, 3, 2008.

MACHADO, Lourdes de Alcantara. O Cadastro Ambiental Rural e as Cotas de Reserva Ambiental no Novo Código Florestal: uma análise de aspectos legais essenciais para a sua implementação. In: Ana Paula Moreira da Silva; Henrique Rodrigues Marques; Regina Helena Rosa Sambuichi (Org.). Mudanças no Código Florestal Brasileiro: Desafios para a Implementação da Nova Lei. Rio de Janeiro, RJ: Ipea/IPC-IG, 2016.

MACHEMER, Patricia; KAPLOWITZ, Michael. A Framework for Evaluating Transferable Development Rights Programmes. Journal of Environmental Planning and Management, Vol. 45, 6, 2002.

MAY, Peter, et. al.. Cotas de Reserva Ambiental no Novo Código Florestal Brasileiro: uma avaliação ex-ante. Publicação Ocasional, No. 146, 2015. Disponível em:

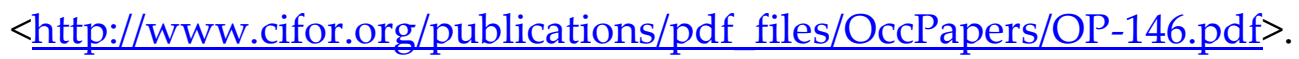
Acesso em: 19 de fevereiro de 2018.

MILARÉ, Édis; MACHADO, Paulo Affonso Leme (Orgs.). Novo Código Florestal Comentado: Comentários à Lei no 12.651, de 25 de maio de 2012, à Lei no 12.727, de 17 de outubro de 2012 e ao Decreto $n^{0}$ 7830, de 17 de outubro de 2012. $2^{\mathrm{a}}$ ed. São Paulo, SP: Revista dos Tribunais, 2013. 
MOTTA, Ronaldo Seroa da. O Uso de Instrumentos Econômicos na

Gestão Ambiental. Rio de Janeiro, RJ: IPEA, 2000.

OSTROM, Elinor; HESS, Charlotte. Private and Common Property

Rights. In: Boudewijn Bouckaert (ed.). Encyclopedia of Law and

Economics, Vol. 5: Property Law and Economics. $2^{\mathrm{a}}$ ed. Northampton, MA: Edward Elgar Publishing, 2010.

PERMAN, Roger, et. al.. Natural Resource and Environmental Economics. 3ํㅡ. ed. Harlow: Pearson Education, 2003.

SANTOS, Laura Meneghel dos; PORTO, Antônio José Maristrello; SAMPAIO, Rômulo Silveira da Rocha. Direitos de Propriedade e Instrumentos Econômicos de Regulação Ambiental: Uma Análise das Atribuições Implícitas. Revista Brasileira de Políticas Públicas, Vol. 7, 2, 2017. Disponível em:

$<$ https://www.publicacoesacademicas.uniceub.br/RBPP/article/view/463 3/pdf $>$. Acesso em: 19 de fevereiro de 2018.

SILVA, Jessica Santos da; RANIERI, Victor Eduardo Lima. O Mecanismo de Compensação de Reserva Legal e suas Implicações Econômicas e Ambientais. Ambiente \& Sociedade, Vol. 17, 1, 2014.

SPAROVEK, Gerd, et. al.. Brazilian Agriculture and Environmental Legislation: Status and Future Challenges. Environmental Science and Technology, Vol. 44, 16, 2010. Disponível em: $<$ http://pubs.acs.org/doi/abs/10.1021/es1007824>. Acesso em 19 de fevereiro de 2018.

TRIPP, James; DUDEK, Daniel. Institutional Guidelines for Designing Successful Transferable Rights Programs. Yale Journal on Regulation, Vol. 6, 2, 1989. 
Cotas de Reserva Ambiental: Uma Interpretação da Análise Econômica do Direito Environmental Reserve Quotas: An Interpretation of the Economic Analysis of Law Submetido em 2017-11-22 Aceito em 2018-01-30

3 JOURNAL OF INSTITUTIONAL STUDIES 2 (2017) 